\title{
Risk analysis during exploitation of mobile scenes
}

\author{
Joanna Wilczarska ${ }^{1 *}$, Michat Sokołowski ${ }^{1}$, Igor Kovtun ${ }^{2}$ and Svitlana Petrashchuk ${ }^{2}$ \\ ${ }^{1}$ Bydgoszcz University of Life Sciences and Technology, Faculty of Mechanical Engineering, \\ Kaliskiego Street 7, 85-796 Bydgoszcz, Poland \\ ${ }^{2}$ Technologies and Design Faculty in Khmelnytskyi National University, Department of Art and \\ Technical Graphics, 11, Instytuts'ka str., Khmelnytskyi, 29016, Ukraine
}

\begin{abstract}
This article discusses the risk of exploitation the mobile scene. The types of such scenes were characterized. Building and traffic regulations for mobile scenes are cited. The selected scene construct and the risks related to its safe operation were characterized.
\end{abstract}

\section{Characteristics of hybrid multimedia mobile scenes}

From the market analysis based on data from GUS shows that the demand for services related to the rental of audiovisual equipment and comprehensive service of outdoor concerts is fluctuating. According to the Central Statistical Office on its websites, in 2019 there were 6,949 mass events in Poland, in which on average about 4,000 people participated in each. It should be noted that the demand for equipment rental is subject to seasonal fluctuations. In the autumn-winter period there is a decrease in interest and in the spring-summer period this trend is reversed. The potential and demand for this type of events together with service in Poland is becoming an important factor both in terms of culture and economy [1].

\subsection{Types of scenes}

The definition on the scene is specified in Dz. U. 2016 poz. 1814 - , the space in which the spectacle takes place, adjacent to the auditorium and separated from it by a building partition with a portal (scene) opening.' There are many different types of scene constructions. These objects are most often made of aluminum trusses along with platforms serving as a flat surface on which the event takes place [2].

The general division of the scenes is shown in Figure 1. Permanent scenes, which are made in accordance with building regulations, include primarily structures located in theaters, operas, etc. Depending on the needs, constructions of this type can take a certain shape and type. Modern constructions allow you to quickly change the scenery using the rotation function or after equipping the scene with additional collapse.

\footnotetext{
* Corresponding author : Joanna.Wilczarska@pbs.edu.pl
} 


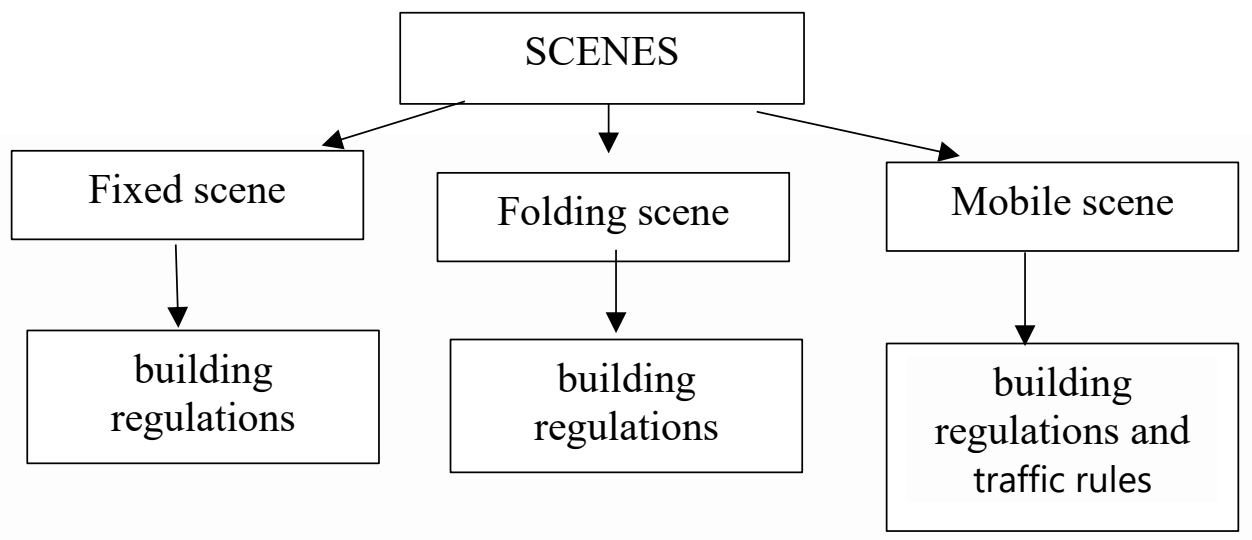

Fig.1. Division of scenes.

Folding constructions concern scenes created primarily from special trusses. The folding scene contains many heavy and large elements. This type of transport must also include a loading and unloading process. Despite this, a scene of this type makes it possible to create a large area. An additional advantage is also the fact that the shape depends on the person ordering. In addition, heavier, and thus stronger elements allow you to mount larger sound systems. Scenes of this type can be used in closed and open spaces. It should be noted that folding scenes similarly to the so-called permanent scenes are mainly subject to building regulations [1].

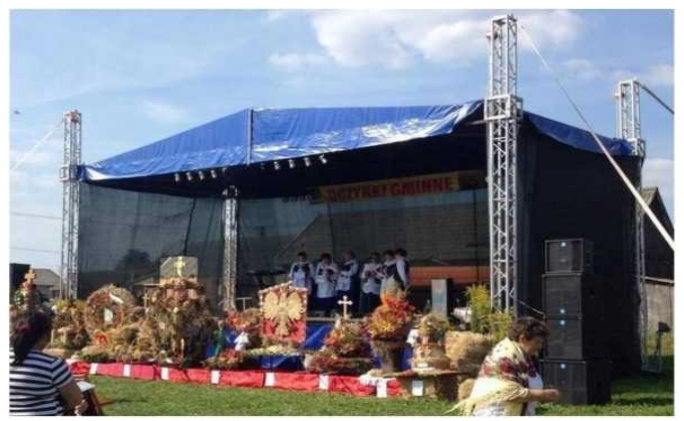

Fig.2. Folding scene.

The last type of scenes that can be distinguished are mobile scenes. The most commonly used scenes today include manually mounted scenes. Structures of this type are built on the ground of a trailer / semi-trailer. Buildings of this type significantly limit the usable area of the entire scene. A different design that allows for quick movement between different types of events is subject to a much wider group of regulations. This is due to the fact that during transport the scene of this type is subject to traffic regulations, and after unfolding the provisions of the construction law [3]. 


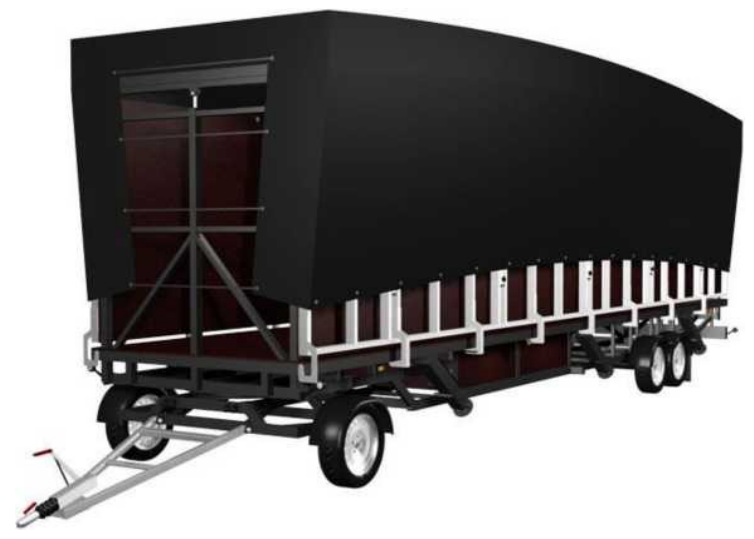

Fig.3. Manually mounted scene.

\subsection{Building regulations}

All scene structures are subject to construction law when used. Mobile and folding scenes according to the provisions of the construction law are the so-called temporary construction objects. According to the law, it is an object "intended for temporary use in a period shorter than its technical durability, intended for transfer to another place or demolition, as well as a construction object not permanently connected to the ground" [4].

The construction law is also supported by the Regulation of the Minister of Infrastructure of 12 April 2002, which specifies the technical conditions that buildings and their location should meet. According to this documentary, the scene is a one-story building with an auditorium from ground level with a roof covering that is at least difficult to ignite the ego. In addition, the electrical installation is made in accordance with PN, there is additional emergency lighting, and the exits and escape passages are in the amount and properties in accordance with PN.

Such facilities must meet the basic requirements set out in Annex I to Regulation (EU) No 305/2011 of the European Parliament and of the Council of 9 March 2011.

Meeting the basic requirements for this type of construction is primarily related to safety requirements. The load-bearing capacity of the structure ordered by the organizer of the show must be appropriate to the number of people using it. No less important safety requirement is to prepare for the eventuality of a fire. Stairs and platforms should be made with an appropriate width to allow all contractors to escape from the place of danger. A temporarily standing scene should also be made of materials that do not affect the environment, which contributes to reducing the negative impact on the protection of the surrounding nature. Manufactured scene structures should thus meet certain standards and have safety certificates allowing objects of this type to be used.

\subsection{Traffic regulations}

Mobile scenes built on the basis of a semi-trailer/trailer during transport are subject to traffic regulations. The basic document is the Act of 20 June 1997 Road Traffic Law. This law defines and clarifies the basic definitions, as well as regulates the rules prevailing in road traffic. According to the above-mentioned law, a trailer is a vehicle not equipped with an engine that can be combined with another vehicle. The definition of a semi-trailer is similar to that of a trailer, because it is a structure which, in addition to not being equipped with an engine, rests on a part of a motor vehicle. It is worth mentioning that when changing the 
structure of a semi-trailer / trailer, additional approval should be applied for. In addition, in order to ensure adequate transport safety, the technical conditions set out in the Regulation of the Minister of Infrastructure of 31 December 2002 must be met. In the case of marking, this will apply to [5]:

Required lighting:

- brake lamp,

- commonly known as 'stop',

- direction indicators - left and right,

- hazard warning lights,

- license plate lighting,

- rear position lamp,

- triangular rear reflectors, side reflectors,

- front reflectors,

- rear fog light.

Strictly defined conditions provide for additional types of lighting :

- if the trailer is wider than 1.6 meters,

- front position lights are also necessary,

- the trailer is wider than $2.1 \mathrm{~m}$ - in addition,

- outline front and rear, a trailer which,

- together with the drawbar,

- $\quad$ is longer than 6 metres must have side position lamps.

The following requirements include the following obligations, for:

- trailers with a GVW exceeding 750kg (for vehicles registered after 01.08.2009) a reversing lamp is required,

- with a GVW of more than 3.5 and a width of more than $2.1 \mathrm{~m}$ - there is a reflective contour marking at the rear,

- for trailers with a GVW of more than 3.5 and a length of more than $6 \mathrm{~m}$ (only vehicles registered after 10.10.2009) side marking is required - reflective contour marking,

- for drawbar trailers and semi-trailers longer than $10 \mathrm{~m}$ or with a GVW of more than 10 tonnes, it must additionally have yellow reflective plates with a fluorescent red circuit.

It is also worth installing speed limit markings on the back of the trailer / semi-trailer because the speed in such a set should not be more than:

- $50 \mathrm{~km} / \mathrm{h}$ in built-up areas

- $70 \mathrm{~km} / \mathrm{h}$ outside built-up areas

- $80 \mathrm{~km} / \mathrm{h}$ on motorways,

- $\quad$ expressways and dual carriageways with at least two lanes.

\section{Exploitation of facilities}

The term "exploitation" means a set of deliberate organizational, technical and economic activities of people with technical devices and mutual relations between them from the moment of taking over the device for use for its intended purpose, until its disposal after liquidation.

Operational activity takes place within logistics, within the framework of various systems producing numerous goods and providing various services. These systems are generally complex and it is not at all easy to separate the exploitation subsystem in them [6]. 
The exploitational strategy consists in determining the ways of using and operating machines and the relationship between them in the light of the adopted criteria.

The following strategies for the operation of machines are known in the literature [7]:

- according to reliability,

- according to economic efficiency,

- according to the amount of work performed,

- according to the technical condition,

- authorized strategy for the operation of machines.

Most often, based on one of the above strategies, the company's exploitation system is built, with elements of other strategies often complementing it. In industrial practice, therefore, mixed exploitation strategies are most often used, adapted to the requirements and conditions of the machines used.

The basic laws governing the exploitation of machinery include [8]:

* each technical device (machine) is an object of exploitation and serves a man to achieve a specific goal;

* the exploitation system consists of a loss and maintenance subsystem;

* there is no object of exploitation that cannot be used;

* there is no exploitation facility that does not require technical maintenance;

* the exploitation facility consumes its operational potential and generates income;

* the exploitation facility regains its operational potential and requires operating expenditure;

* the process of exploitation of the facility is carried out within a specified period of time.

\section{HMSM scene construction}

The mobile scene is most often based on trailer constructions. The designers of HMSM followed a similar path, however, to ensure a larger size of the scene itself, they decided to base their construction on a semi-trailer. The structure is built on a platform semi-trailer with dimensions of $13.3 \mathrm{~m}$ in length and $1.86 \mathrm{~m}$ wide within the values specified in the Regulation of the Minister of Infrastructure of 31 December 2002 on the technical conditions of vehicles and the scope of their necessary equipment [3].

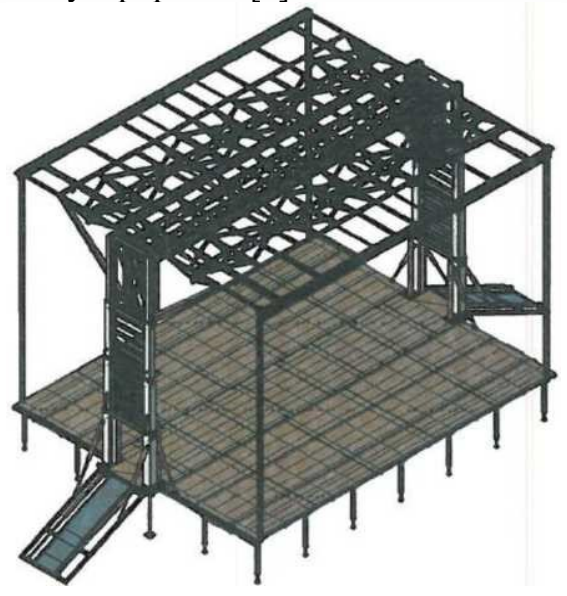

Fig.4. Scene HMSM.

The design consists of three basic systems: 
- Folding scene platform,

- Extendable roof,

- The system of hudralic actuators.

The scene platform is the main element of the scene. The project assumes the implementation of this system from steel in the form of trusses. The area of the scene platform is over $120 \mathrm{~m}^{2}$. This size of surface area was achieved thanks to the system of hydraulic cylinders, which allow not only to spread the platform to the sides, but also to move the structure apart.

The roof is first raised to a height of over $9 \mathrm{~m}$ by means of masts equipped with hydraulic cylinders located on the front and the back of the semi-trailer. The structure of the roof itself, like the scene itself, is based on trusses combined with each other ensuring the required stability of the structure. On the roof itself, apart from the tarpauline covering the participants using the scene, there will be photovaltaic panels that will allow to power the used electrical receivers mounted for the duration of the scene's use. This solution will not only reduce the costs of handling the scene, but also have a positive impact on environmental protection.

The most important arrangement of the whole scene is the hydraulic system. The implementation of this solution makes the currently produced mobile scenes independent. The applied set of actuators is to enable the installation of individual segments of the floor and roof structure. An additional task of the above-mentioned system is to level the structure in the area where it will be used. This is the first and most important process determining the stability of the structure $[1,3]$.

The hydraulic system is at the heart of the entire hybrid design of the multimedia mobile scene. The system is based on modern safety regulations, which have undergone a lot of evolution of safety requirements over the past years. This is primarily due to the more widespread use of this type of systems in increasingly complex technical solutions. The safety assessment of systems in which the working medium is a liquid can be carried out on the basis of the Regulation of the Minister of Economy on the essential requirements for machines of 21 October 2008 implementing the Machinery Directive. According to these regulations, the safety of the entire system depends on the appropriate selection of system parameters, the elements used (primarily all gaskets), as well as the selection of the right hydraulic fluid. The standard that specifies both hazards and requirements for the design and use of the hydraulic system is PN-EN ISO 4413:2011. Systems of this type are often responsible for the safety of using machines, which requires that they be made with due accuracy. It was noted how important the arrangements between the contractor of the system and the machine manufacturer are and a model form was proposed to regulate this issue [1].

In order to assess the conformity of a machine, use the available standards and the Machinery Directive. If there is a type $\mathrm{C}$ standard for a given construction (it contains detailed safety requirements), the machine should be checked according to this standard and then proceed to the assessment of the main safety requirements according to the Machinery Directive. However, where there is no type C standard, type A standards (general design principles with key concepts) and B (general safety standards for a wide range of machinery) should be used and then the safety requirements should be assessed on the basis of the Machinery Directive. The risk assessment of hydraulic control systems is carried out on the subject of PN-EN ISO 13849-1:2008.

\section{Changes for individual hazards}

If you want to reduce the risk value, it should be noted that it is difficult to influence the "severity of the injury" and only attempts can be made to reduce the incidence of the threat. The HMSM scene is designed and executed with the highest safety guidelines, but nevertheless due to the nature of the technical facility there are some risks. The primary 
hazard that generates a huge risk is falling from a height. In the case of this structure, a fall can occur both from the floor surface of the scene and from the roof itself, on which maintenance must be carried out. In the case of this hazard, the parameter "severity of damage" takes the highest value - 5, while the "frequency of the event" has been determined at level 3. In order to be able to reduce the value of this threat, it is worth making some improvements to the design. In the event of a fall of the roof maintenance person, a special protection system can be introduced on this surface to attach the harness of the person performing the maintenance. This system could be special anchoring ears as well as ridge rails (Fig.5). These elements would allow the person performing the maintenance to connect with a harness to them, which would have a positive impact on the safety of use [9].

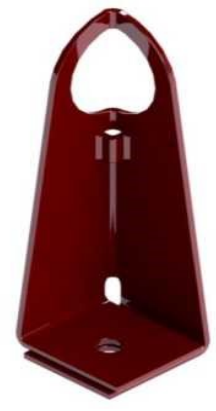

Fig.5. Anchoring ear.

Falling from the surface of the scene is one of the also dangerous threats that this type of construction brings. Due to the better visibility of people present on this type of facility, no additional barriers are used. The basis for protecting people from falling is to mark the edge of the ground with special tapes. However, it is worth enriching this protection with special mounting places made in the construction of the ground intended for placing recessed barriers made of lightweight materials such as aluminum or plastic.

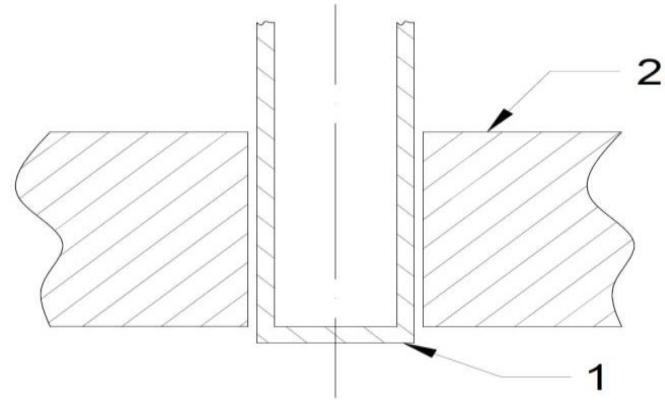

Fig.6. Installation place for fall barriers: 1 - railing leg, 2 - construction of the scene substrate.

The installation places made could be made around the entire floor, which would allow to mount the berks in such a way that they do not interfere with the reception of the performances.

Another high-risk hazard is the possibility of pinching limbs while mounting the scene. The basis for securing people in close contact with the scene is to make sure that no one is around the places that generate such a risk. However, in addition to this, it is also possible to eliminate such a risk through appropriate design solutions. The first solution that is currently missing from this design, and which can improve safety, is the installation of warning devices. It is possible to install special warning lamps that would emit a flash during the 
assembly of the scene informing about the following assembly process (Fig.7). These lights should be located primarily on the edges of which the assembly process takes place.

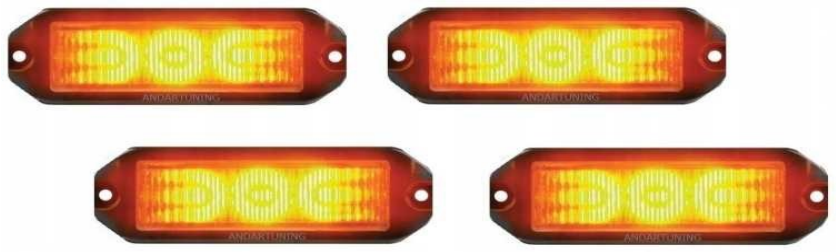

Fig.7. Warning lamps.

The flash system should be supplemented with additional warning signals that allow not only to see the assembly process taking place, but also to hear. This would significantly affect the safety of using the structure. Another solution to this threat is the use of electromagnetic safety sensors. Sensors of this type provide non-contact and safe detection of both objects and people. A set of this type of sensors creates the so-called safety curtain after entering which the machine immediately stops ensuring the safety of the operator (Fig. 8) [10].

Another hazard that must be eliminated both due to the severity of the damage and the frequency of the event is the risk of burning a hydraulic pump. The hydraulic system is one of the systems that generate temperature during operation. Maintenance requires looking into every corner of the machine to ensure the safety of its use. A working hydraulic pump generates heat, which at the time of contact with the skin can lead to a burn. To prevent this, it is worth placing the pump in a special heat shield, which will not only reduce the risk associated with burns, but also protect the pump against stone impacts during transport.

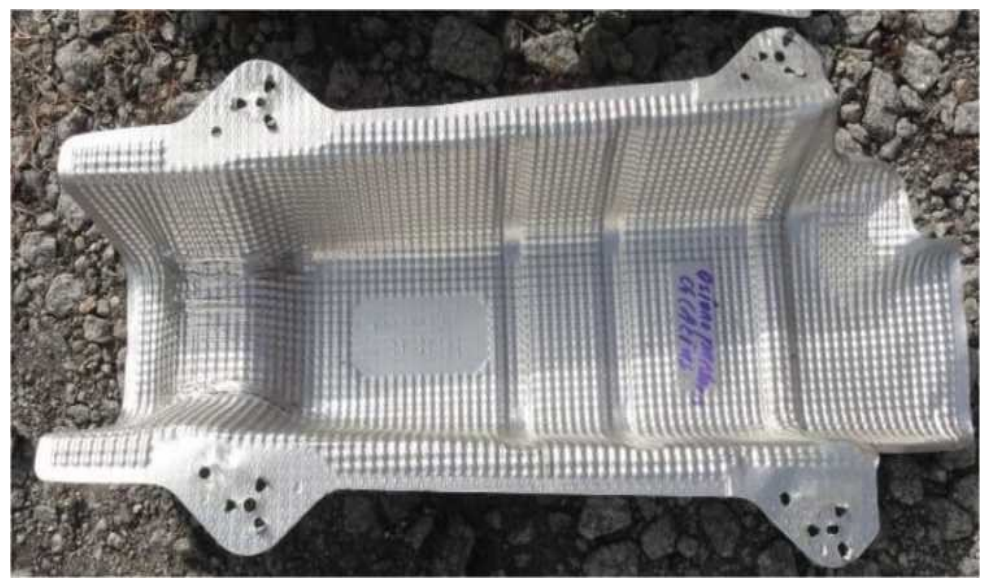

Fig.8. Heat shield.

Covers of this type are made of lightweight corrosion-resistant materials such as aluminum or stainless steel. The task of the pump in the hydraulic system is to generate the right pressure allowing for the proper operation of the entire system. To prevent leakage of hydraulic fluid under high pressure, which can lead to an accident and cause burns, the entire system of hydraulic lines and cylinders should be covered. A sheathed system of cables made of appropriate materials will reduce the risk associated with the maintenance of such a system. Systematic maintenance of the system also contributes to reducing the risks associated with its operation. Therefore, the instruction manual should contain information on this. 
Another risk belonging to the acceptable risk group is the risk associated with falling when entering the scene. To be able to get on the scene it is necessary to design and create stairs. The ground of the scene located at a height of more than $1.2 \mathrm{~m}$ at the time of the fall can lead to many different injuries. The stairs used in this type of construction must be:

- made of materials resistant to corrosion and moisture,

- have barriers to catch and protection against falling,

- $\quad$ steps should be marked with tapes, guarantee the possibility of slippage,

- the width of the stairs should allow for the safe evacuation of persons on scene.

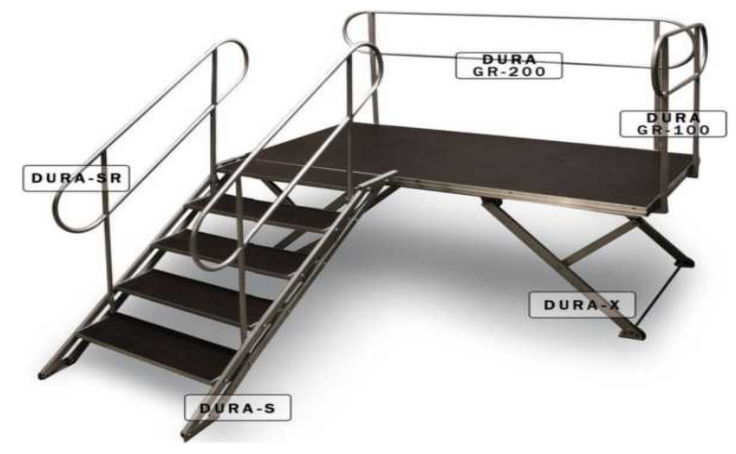

Fig.9. Modular stairs.

Other hazards are difficult to compensate for by means of structural changes $[10,11]$ :

- Impact on structural elements during maintenance,

- Shock Loss of stability due to gusts of wind,

- Loss of stability of the vehicle combination during transport.

The above hazards belong to the so-called residual risk, i.e. a risk that cannot be eliminated by structural solutions, but should only be specified in the instruction manual and special precautions should be recommended. In the case of risk associated with hitting structural elements that contain sharp edges, it is worth using personal protective equipment such as a helmet and gloves. These measures will reduce the severity parameter of the damage, which will reduce the risk value as a result. The number, type and quality of electrical equipment that will be on the scene during its operation are mainly the responsibility of the performers. The constructor is not able to predict in what condition individual electricity consumers will be. Information about the risk of electric shock should be included in the instructions along with information on what values should not be exceeded. In addition, electrical appliances should be checked for condition before each use. A huge screen with an area of over $50 \mathrm{~m}^{2}$ in the case of gusts of wind can become a kind of "sail", which with sudden gusts of high-speed wind can lead to a loss of stability of the structure. The HMSM structure is protected against this type of threat by means of a self-leveling system, the use of additional supports, etc. however, the risk may still exist. Therefore, in the instruction manual, despite being informed about this type of threat, it is worth including information about how to set the scene [12-14]. 
Fig.10. Anemometer.

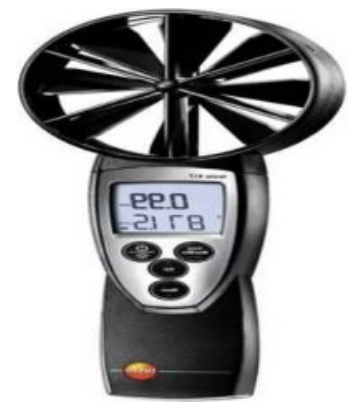

With the use of an anemometer (Fig.10) it is possible to measure both the wind speed and the direction itself. After making such measurements, it is possible to determine how it is worth setting the scene so that sudden gusts do not lead to uncontrolled loss of stability. It should be remembered that the place where the structure will stand is also important. The ground should be properly hardened and, if possible, even. The way the scene is set and the weather conditions do not depend on the constructor, who is not able to counteract this type of threat. To carry out a risk analysis, it is necessary to determine what elements and systems a specific object consists of. Such a division makes it easier to determine the risks that the structure carries. The HMSM scene has been divided into elements/layouts [11].

\section{Summary}

The construction of the Hybrid Multimedia Mobile Scene should be made in compliance with the latest safety standards at the design scene. The structure should not only meet the requirements set out in the standard on the principles of design of this type of objects, but also the requirements set out both in the construction law. No less important aspect is the scene control system, which should be prepared in accordance with the requirements set out in the relevant standard. The selected threats are mostly related to the specificity of the scene type object. The constructor has no influence on the quality of the equipment used when using the scene. Therefore, it is worth including in the instructions recommendations for the maximum loads of the structure and the electrical system, as well as recommend the use of equipment that meets electrical safety standards.

This paper has been achieved under the research project "Hybrid multimedia mobile scenes are a chance for decisive innovation" No. POIR.04.01.04-00-0045/17-00

\section{References}

1. M.Liss, T. Kałaczyński, N.Dluhunovych. Strength analysis with wind influence on a hybrid multimedia mobile scene. ENGINEERING MECHANICS. Svratka, Czech Republic (2020)

2. Dz. U. 2016 poz. 1814 OBWIESZCZENIEMINISTRA KULTURY I DZIEDZICTWA NARODOWEGO z dnia 19 października 2016 r. w sprawie ogłoszenia jednolitego tekstu rozporządzenia Ministra Kultury i Dziedzictwa Narodowego w sprawie bezpieczeństwa i higieny pracy przy organizacji i realizacji widowisk

3. M.Liss, T.Kałaczyński, N.Dluhunovych, A.Dykha, R.Martinod. Identification of loads of the construction of a Hybrid Multimedia Mobile Stage. Matec Web of Conferences (2021)

4. Dz. U. 1994 nr 89 poz. 414 USTAWA z dnia 7 lipca 1994 r. Prawo budowlane 
5. A.Sołtysiak, K.Migawa. Application of the Pareto front for risk control in the transport system. Matec Web of Conferences. (2019).

6. M.Łukasiewicz, M.Liss, N.Dluhunowych. Analysis of vibrodiagnostics methods in the technical state study of designed multimedia mobile scenes . Matec Web of Conferences. Bydgoszcz (2021)

7. J.Wilczarska, E.Kuliś, M.Łukasiewicz, Ł.Fornal, N.Dluhunovych. The assessment of the impact of the chosen exploational conditions of hydraulic arrangement on the working liquid condition. Matec Web of Conferences. Pieczyska (2018)

8. V.Martynyuk, J.Boiko, M.Łukasiewicz, E.Kuliś , J.Musiał. Diagnostics of Solar Cells. Matec Web of Conferences. (2019)

9. M.Dąbrowski, Wymagania bezpieczeństwa dotyczace układów hydraulicznych w stacjonarnych maszynach przemystowych, MECHANIK NR 2/2013, strony 123-126 (2013)

10. M.Dźwiarek. Ocena ryzyka przy projektowaniu maszyn wg dyrektywy 2006/42/WE oprogramowanie narzędziowe PRO-M, Napędy i Sterowanie (2009)

11. M.Kusiak. Ocena ryzyka $z$ wykorzystaniem norm zharmonizowanych EN 62061 oraz EN 13849-1 Jachranka (2009).

12. M. Markiewicz, Ł. Muślewski, Survey performence and emissionparameters of diesel engine poweredby diesel oil and fatty acid methyl esters using fuzzy logic techniques, Fuel, 277 (2020)

13. M. Markiewicz, Ł. Muslewski, The impact of powering an engine with fuels from reneweble energy sources inclouding its softwere modification on a drive unit performance parameters. Sustainaibility 11, 23 (2019)

14. B. Landowski, M. Baran, Analysis of selected results of engine oil tests, MATEC Web of Conferences 302, 01010 (2019), 18th International Conference Diagnostics of Machines and Vehicles, pp.1-7 (2019), https://doi.org/10.1051/matecconf/201930201010. 